\title{
The Countermeasures of Enhancing Government's Credibility since We Media Era
}

\author{
Jiang Ke \\ School of Public Management, Yunnan University of Finance and Economics, Kunming, P.R. China
}

( E-mail: 1341824069@qq.com )

\begin{abstract}
With the development of Internet and information technology, China has entered the information of the digital age. In recent years, China's rapid development from the media, government credibility questioned and challenged by the unprecedented. Management deficiencies by the government itself, the laws and regulations are not sound, and since the media's own character is the reason for the credibility of the government missing. To improve the credibility of our government should establish an effective supervision mechanism and information disclosure system, and strengthen the construction of laws and regulations, in order to effectively safeguard the image of the government to enhance the credibility of the government.
\end{abstract}

Keywords: We Media; Government; Credibility

\section{Introduction}

With the rapid development of the Internet and communication technologies, the Internet and wireless network information dissemination platform, computers, mobile phones and other wireless devices to a terminal, based on personal communication media age, everyone has a microphone, everyone is a reporter everyone is a news disseminator, each account is like a small media. The basis of this medium by virtue of its interactivity, autonomy characteristics, making the Freedom of the Press has significantly improved, the media ecology unprecedented shift. But since the arrival of the media age, but also to the credibility of our government brought a severe test. The government faces credibility in the era of we media information disclosure and political oversight, expression of will and agenda setting, the presence of the crowd and the pressure of public opinion, the impact of the four levels of political mobilization and action organization.

2010 called micro blogging first year in 2011, known as the government micro blogging first year. As from the media a government micro blogging has become a platform and an important channel for the government to communicate with Internet users, listen to the public voice of. Should be a rational view of micro blogging, to strengthen the transformation and interaction as the core, and actively promote political modernization and openness in government affairs and administrative information technology.

\section{Since the Credibility of the Media and Our Government Development Status}

\subsection{Since the Media Development and Its Characteristic}

From the media, the general public, via digital technology strengthen connected with the global knowledge system, one began to understand how the general public to share their own facts, their news channels. Private, civilians, general generalization, the disseminators of autonomy, a modern, electronic means, to pass the new media, the general term of normative and non-normative information not specific to the most specific single individual blog just one way. Since the media has the following characteristics.[1]

2.1.1 Civilians, personalized. Promoting in he media, the people, the transition from "bystander" to become a "party", every civilian can have a copy of your online newspaper "(blog)" webcasts "or" network TV "(podcast). "Media" as if overnight, "flying into the homes of ordinary people, into a personal communication carriers. Independently in the "media", "wanted to write to write the" Xiang shui jiu shuo, each of the "grass-roots" can use the Internet to express the point of view they want to express, to pass their own life wanes Build your own social network. Civilians since the media has become mass individuality and self-expression of the best place to. 
2.1.2 Low threshold, the operation is simple. Television, newspapers and other traditional media, the media operation is a complex matter, and it takes a lot of manpower and financial resources to maintain. And in the era of highly developed Internet culture, we sit at home and you can see the beautiful scenery of the various parts of the world, you can enjoy the latest popular audio-visual, you can taste the major masters of Jiyangyenzi . Internet seems so " Anything is possible, "the civilian population to set up a own" media "is also possible. Sina blog, Youku broadcast off, etc. all provided from the media's website, the user only needs a simple registration application according to the service provider network space and optional templates, you can take advantage of the layout management tools, network publish text, music , pictures, video and other information, to create their own "media. Own the media, you do not need to invest any cost, do not require you to have any technical expertise. Low barriers to entry, the operation of the operation is simple, so that from the media popular rapid development.

2.1.3 Interactive, and spread rapidly. The development of digital technology, without time and space constraints, any time, any place, we are able to run their own media, information can be spread quickly, timeliness greatly enhanced. Works from production to quickly and efficiently, traditional television, newspapers and the media can not match. Since the media can quickly dissemination of information to the audience, the audience can also be quick feedback on the effect of information dissemination. Is zero, since the distance between media and audience interactive powerful is unmatched by any traditional media.[2]

2.1.4 Good and bad, low confidence. Everyone has a different attitude, on behalf of the individual from the media also varies greatly. People can self-established "media", when the master of the media, information published entirely in accordance with their own wishes want to edit. Some of this information itemized account records of the chores of life, plenty of highlights profound insights on life circumstances, some observations on the current political comments, some of the professional knowledge of exploration and thinking ...

Network, since a large number of media, its owners are mostly for "grassroots" civilian network occult to the netizens "free" space. Civilians the right to speak to be done today, more and more people have something to say. Some speed pursuit of a news release from the media over or ignore the authenticity of the news in order to pursue the click-through rate, the result in part of folk writers reduce the moral bottom line. This led to the credibility of the information spread since the media.[3]

The world's Internet users has exceeded 20 million, has more than 50 million mobile phone users. China Internet Network Information Center (CNNIC) in Beijing released 31 "China Internet Network Development Statistics report" as of the end of December 2012, our micro blogging users scale to 309 million, as compared to the end of 2011 an increase of 58.73 million, Internet users in the micro- Bo user ratio reached $54.7 \%$. Phone micro blogging users scale of 202 million, accounting for $65.6 \%$ of all micro blogging users, nearly two-thirds of the overall number. China's mobile phone users reach 356 million up 17.5.[4] China has become the new media superpower.

\subsection{The Development Status of China's Government Credibility}

Credible connotations derived from the concept of "credit" and "integrity". Credibility connotation understanding of credit from the government level. The so-called government credibility from the government credit, the Government to fulfill its own responsibility and obligation thus keep its commitment to the public to get the public heart of the government's modus operandi, the administrative action of the government executives and government action, the entire social system understanding and trust, and make an overall evaluation. Fundamentally speaking. The credibility of the government is the degree of public trust in government, public, government acts directly bear timely feedback and evaluation of government action to give the feeling. The level of credibility of the government reflects the people's trust in the government, thereby affecting the government's image in the eyes of the people and influence. If the public trust means the public on the government to give a good evaluation of the credibility of the government; otherwise that the low credibility of the government. Therefore, the credibility of the government is the measure of modern government is not an important indicator of the effective government and building a harmonious society in China and promote the construction of service government are closely related.[5]

Our government has been fully aware of the important impact in our undertakings and from the media. As the government micro blogging from one of the forms of media has become a platform and an important channel for the government to communicate with Internet users, listen to the public voice of. January 8, 2012, the authority of the e-government research center of the National School of Administration issued 
government micro-blog Assessment Report of China 2011 "report shows that as of the end of last year, the Chinese government micro-blog a total of 50,561, an increase of $776.58 \%$ compared to early 2011. Sina, Tencent, People's Daily, Xinhua four micro-blog site certified party and government agencies micro blog 32,358 certified party and government cadres micro blog 18,203. 2011 New certification Party and government institutions micro blog 27,400 17,393 new certification party and government cadres micro blog.[6] only from figures indicates that China's government departments at all levels also joined the micro blogging craze among. The establishment of a wide range of government micro blogging China to promote the democratization process in the highlights the efficiency and effectiveness of the implementation to be further enhanced.

Yong wen line of 7 - 23 motor car accident in 2011, Mei-US designer handbags, small Yue Yue event, the reason why things happen the first time to become widespread concern about the hot spots are inseparable from the media the also being With the majority of the people can be kept informed of the true situation of things, from the media platform. 7 - 23 Yongwen line motor car accident, the public questioned the existence of accident fatalities and injuries, as well as rescue situation. CPA exam, judicial examination, physician examination, national construction division examinations held in September 2011, a series of four national qualifying examination exposed declared yesterday events online, the public and the media widely called on the government to conduct a thorough investigation into the truth, and give a clear findings. These events also reflect the lack of government response mechanisms and the lack of credibility of the government again.[7]

\section{The Root of the Government's Credibility Deficiency Since the Media Age}

\subsection{The Regulatory Mechanisms are Inadequate, and Government Officials of Corruption, Lack of Accountability}

The melamine of SanLu, waste oil, wine pesticides door "made of leather scraps medicinal capsules food safety incidents, major traffic accidents, mine and so on some government departments are fully exposed to the lack of effective supervision and management mechanism. Government administration is not as vacancy behavior. Some government officials lack a sense of crisis. Their own lack of a sense of responsibility and civic-minded. Some government officials entrusted by the people to their rights as a tool for their own profit, abuse of power, bribery and corruption, low style. Broke once since the media era scandals quickly aroused public discontent, while allowing the public to serious doubts about the credibility of the Government.

\subsection{The Government's Response is Inefficiency and the Government Makes Public Absent}

Government information disclosure is to protect citizens' right to know, to promote government and the public to interact, to enhance the credibility of the Government of the basis. But the government did not effectively do the transparency of information, often before a public information to their advantage, deliberately conceal adverse information or false reporting. When major emergencies occur, often the first time to respond to the public at large, through broadcast these events since the media will be the first time out, the government's response is often to wait until the event has caused heated debate before. For example, the Sanya tourism Zaike incident initially that tourists microblogging exposure, after quickly aroused public sympathy. Under the pressure of public opinion the Sanya government began to intervene in the investigation. But why local governments are not taken before the truth is exposed positive regulatory measures? Measures taken by the majority of people questioned in the case had already suffered the loss of many tourists, no doubt the government into a passive. This information public as well as respond to inefficiencies will not only lead to the negative impact of the incident and the seriousness of the situation to expand and cause the public generally questioned the credibility of the government.[8]

\subsection{Since the Media Era Civil Rights \\ Awareness}

Since the role of the media, the public's awareness of their rights to express their views to further enhance demands more apparent. Since the media so that the public no longer completely passive acceptance of top-down indoctrination and standing source of information through new media to obtain and publish a variety of information resources. Embodies the characteristics of we media era, "everyone is a reporter, everyone can sound". Any comments of the public can come out and aroused the concern of to these factors posed a great challenge to the credibility of the government. 


\subsection{Public's Opinion is Instable}

Since the emergence of the media so that the general public can provide and share their own facts, news of their own. Microblogging, for example, the user can freely post forwarding, review information on the microblogging difficile true to the competent authorities or those involved, this collection of judgments network public opinion brought huge challenges. Unstable trend of public opinion. Occurred in recent years, such as "Japan nuclear radiation air arrived there," a college party secretary in Zhejiang open room caught "," female students in Wuhan cut kidney are typical public special information to attract will be widely disseminated to the credibility of the government caused the very serious consequences, they were proved to be false information.[9]

\subsection{Inadequate Laws and Regulations}

Our system is not perfect. In many respects the laws and regulations did not specify whether it should be public information, not public and also did not give appropriate treatment program. Also attempt to justify, especially when it comes to the negative news of the government or government officials, the government and officials often deliberately blocked information publicly or attempt to cover up the truth, even in the public use of various media resources to find out the truth, prevarication or "pass the buck". Since the reason why the media lead to rumors flooding but also because the public lack of awareness of the law on the one hand, does not understand the to spread rumors hazards and liability, on the other hand, the lack of awareness of self-protection. Therefore, the laws and regulations of our country needs to be improved. To ensure the credibility of the government from the legal system must be constrained.

\section{The Strategy of Enhancing the Government's Implementation and Credibility}

\subsection{The Establishment of the Government Holistic Response Mechanism}

To ensure the credibility of the government, the first government departments to integrate their respective duties, concerted encounter unexpected problems can complement each other, and be able to share information resources. Second, the government should carry out the public-private partnership, the establishment of inter-agency information processing mechanism. Government can be combined with social organizations, opinion leaders, various media terminal Organization survey on social issues in a timely manner, and timely disclosure of timely treatment, the facts tell the truth to the public at large. True and false distinction on the basis of we media era, the government even more with some network crackdown elite "cooperation, scientific or factual basis to clarify the various rumors, maintain the stability of the network, and to give the public a clear and credible answer. Through cross-border cooperation and communication, to achieve the government-media era holistic governance model.

\subsection{Strengthening Administration Force According to Law Enforcement}

No rules no standards. Improve government efficiency, enhance executive power and credibility, strictly in accordance with the statutory authority and procedures for the exercise of powers is a prerequisite and guarantee. We should conscientiously implement the "power comes with responsibility, with the right subject to supervision, illegal should be investigated for" requirements, to promote the rule of law and government construction. To improve legal literacy. Governments at all levels must often organized in various forms and the study of law activities, focusing on learning the new laws and regulations, abide by the law, in accordance with the law, and enhance the legal awareness. To standardize law enforcement activities. Must be strictly in accordance with the requirements of administrative law enforcement responsibility to adhere to humane law enforcement, affectionate law enforcement and civilized law enforcement to do neither ultra vires chaos as not dereliction of duty not as. To refine administrative discretion, put an end to the "relationship", "opportunities" not fine or a slap phenomenon.

\subsection{Strengthening the Construction of Laws and Regulations, the Establishment of an Effective Supervision Mechanism}

To improve the relevant laws and regulations from the media as soon as possible, a clear definition and description of the network behavior of the government, enterprises and individual citizens. Many websites implement real-name system registration necessary premise to expand the scope of application of the real-name system, to strengthen the strict real-name certification. Institutionally in information disclosure, it is necessary to further clarify and refine the scope of disclosure, while clearly not in accordance with the law of information disclosure penalties. For the personal use of the behavior of a variety of information from the media release, the law should further clearly explained on whether to publish rumors, infringement, leaks, etc., but 
also strict and clear penalties for wrongful conduct. [8] In addition, the government should increase publicity and education efforts since the relevant laws and regulations of the media people, so that every citizen understanding of living need to follow a code of conduct to safeguard the credibility of the government to lay the foundation.

The government should establish a good credibility, it is necessary to let the community and the public to carry out effective supervision of their own. Through official websites, micro blogging, mobile TV, the establishment of a special supervision channel, receiving masses feedback in a timely manner. The government can not be too much interference in the media coverage and publicity, from the past "seal", "blocking", "pressure" mode $\square$ transformed in order to encourage communication, collaboration model, and for the first time, the answer is given. Government to accept supervision from the different channels, and the public to play a major oversight, supervision of the government, the media, and the operation of the organization.

\subsection{The Establishment of an Open and Effective Information System}

Information disclosure relating to the protection of the right to citizens to understand, and the understanding of the right to be necessary to limit the legal system. First, it is necessary to improve the system spokesman. Press release should be timely, the norm. Government to master cutting-edge information, authoritative the $\square$ grasp the principle of agenda setting. After the occurrence of unexpected events, the government should take the initiative to publish for the first time events such as information, can not have a wide impact or rumors and then released, so that the government into a passive position. The press conference can not be confined to sudden major events, the government should always livelihood issues of concern to the people answering questions. Second to further strengthen the system of public hearings. Hearing system in China started late, the mainly existence of public participation is not high, narrow hearings surface, the result of the hearing is not open, not timely information to respond to the problem since the media age has become an important factor affecting the credibility of the government. Therefore should strengthen and improve the system of public hearings into the decision-making scope.[10]

\section{Conclusion}

Since the emergence of the media, micro blogging, many focus on hot events have played an important role in promoting this drive is not only society, but also on traditional media to promote. Driven from the media, the traditional media have become faster, more sensitive, even in terms of management style, management had to give more and more traditional media freedom, increasing space. The government should be fully aware of the necessity of we media era of citizen participation in public events, the correct treatment of the public remarks, timely processing of each link, and to prevent grievances accumulated result in the deterioration of emergencies. Improve the government's ability to respond to emergencies, and supervise the part of the government officials of corruption, strengthen the transparency of the operation of government policies, and establish a good image governments, reshaping the credibility of the government.

\section{References}

[1] The definition and characteristic of we media [EB/OL]http://news.xiaodao360.com/ article-16206-1.html/2012-10-24.

[2] Nie Bokui. The role of new media in my government crisis management $[\mathrm{J}]$. South China University of Technology (Social Sciences), 2010 (4). (In Chinese)

[3] Feeebook study subvert the six degrees of separation theory [EB/OL]. The http:// www.sins.COllLcn/i/ 2011-11-22, 16576365541.shtml,2012.1.10

[4] CNNIC published "31 China Internet Development Status Survey report [EB/OL] http://www.clmic.net.en/dtygg/ dtgg/201201/1201201/ 16-23667.html. 2012.2.10of.10

[5] Leaves South off the basic connotation with the upgrade path of the credibility of the government [EB/OL]. The http://www. op6r.gov.en/the/zlzx/zjxr./201202/ t20120202-29761.htm.2012.2.10

[6] The evaluating report of the government affairs'micro-blogger in 2011.http://news. xinhuanet.com/politics/2012-02/08/ c_111502121.htm/2012-02-08

[7] "microblogging with governance" should be strengthened. Efficiency "explore http://teeh. hexun.cmw'2012-02-13 138176163.html. 2012.2.20

[8] microblogging public opinion. Fragmentation chain tornado [EB/OL] http://www.solo. gov.en/ cbw /qk/ 42011-08-201108/ t993717.htm.2012.2.20 
[9] Thomas $\bullet R \cdot$ Dey. Understand public policies [M] Beijing: China Press, 2004.

[10] Gao Hong-Ling network public opinion and social stability [M] Beijing: Xinhua Publishing House, 2011. (In Chinese) 